but in some cases this haemorrhagic pattern is very obvious. If one considers these pictures in conjunction with some of those illustrating the paper of Michaelson and Campbell (1940) the resemblance between the capillary-free zone of the injected retina and the blood-free zone in retinal haemorrhage is sufficiently striking to suggest that the latter is found in those cases where the haemorrhage has taken place from the capillary plexus internal to the inner nuclear layer.

It is outside the scope of this paper to deal with the preparation of the microscopic sections, which follows the usual lines. My purpose has been to point out that much essential information may be hidden in the gap between the ophthalmoscopic examination and the examination of paraffin or celloidin sections ; and to show how complete a survey of the normal and abnormal histology of the retina can be obtained by the serial application of the methods described.

\title{
REFERENCES
}

Sorsby, A. (1937).-Proc. Roy. Soc. Med., Section of Ophthalmology, Vol. XXX, Pt. 1 .

(1939).-(a) Brit. Jl. Ophthal., Vol. XXIII, p. 20 ; (b) Trans. Ophthal. Soc. U.K., Vol. LXIX, p 727.

Zamenhoff (1930).-Arch.f. Ophthal., Vol. CXXIV, p. 87.

GOLDMANN (1938).--Ophthalmologica, Vol. XCVI, p. 90.

BEDELI (1937).-Trans. Ophthal. Soc. U.K., Vol. LVII, p. 468.

- (1939).-Trans. Ophthal. Soc. U.K., Vol. LIX, p. 219.

Michaelson and CAM PBELl (1940).-Trans. Ophthal. Soc. U.K., Vol. LX, p. 71

\section{A CASE OF BOECK'S SARCOIDOSIS}

BY

\author{
E. V. SRINIVASAN
}

MYLAPORE, MADRAS

MRS. L., aged 45 years, with cataract in both eyes, with absolutely no contra-indication for immediate operation, had an extraction performed in the left eye, the right eye being quite immature. She was discharged as satisfactory within a month with correction for the operated eye. She returned a month later with signs of cyclitis in the operated eye. After getting the usual treatment for about five months she disappeared without being completely cured, but reappeared in a month's time with pain and marked loss of vision in the eye.

On examination she had well-marked ptosis of the left eyelid. Underneath, the eye was tender with deep keratitis, vascularisation obscuring deeper details as it extended nearly to the upper twothirds of the cornea. Tension was low. The clear lower cornea 
revealed a lot of precipitates. The iris that could be vaguely seen had three or four large rough and irregular reddish-yellow nodulesnot of the mutton-fat tubercular type.

What made me think of this case being one of sarcoidosis was the new and additional feature which was not present in the beginning. It was the upper fornix that was full, the skin of the lid having no sulcus between the globe and the superior orbital margin. Palpation detected a hard nodular tender mass. This cartilaginous mass could be pushed behind between the globe and the orbital roof having no adhesion to either. Transversely it occupied the mesial three-quarters of the upper fornix having apparently no connection with the lacrymal gland. The posterior limit of the tumour could not be determined though it must be said that it could not be larger than a big almond seed as there was no displacement of the globe and no proptosis. There was no limitation of the eye movements. The fornix conjunctivae had been drawn up by the tumour being adherent to it and could not be seen on everting the lid and making the patient look down severely. The rest of the conjunctiva presented a normal appearance, having no papillae or follicles.

The next feature of still greater confirmatory character was the myxoedematous skin. It was dry and thickened over the cheeks, neck and shoulders, and the upper extremities. The hard and rubbery feel of the skin was something unusual in this otherwise flabby and plethoric individual. The thickness was more or less diffuse in the areas mentioned, though only one solitary circumscribed area of this thickened skin was seen in the outer aspect of the right forearm. The skin of the lower extremities and the rest of the body was normal.

Radiographs of the chest showed enlarged hila with a few calcareous glands, diffuse fibrosis of the lung fields and a few calcified foci. Slight widening of the superior mediastinum towards the right suggested enlarged paratracheal glands. The diaphragm was pulled up on either side as a result of adhesions.

Spleen and liver were normal. There was no enlargement of the lymphatic glands. No history of syphilis or tubercle. Latterly the patient had been having irregular fever. Mantoux test, negative. Biopsy was not done as the tumour was unduly painful in the beginning.

A fortnight of daily general ultra-violet radiation seems to have had distinctly beneficial effect on the tumour, as it showed marked decrease in size, pain having almost disappeared. The cornea was getting clearer and the uveitis improving, though the tension continued to be low. This spontaneous resolution of the tumour characteristic of sarcoidosis made me feel quite indifferent about the biopsy. The tumour is getting harder as it is getting smaller with certainly no sign of softening or caseation. 
So far, no case of sarcoidosis has been reported with painful tumours. It is also extremely rare to see a case of mixed sarcoid as mine with uveitis and subconjunctival tumour at the same time. Almost a similar case of Boeck's sarcoidosis of the lacrimal gland has been reported by Stallard, but there was no uveitis. And a number of cases of Boeck's iritis have been published, but not with an orbital tumour in any.

The fortuitous onset of the disease in my patient is rather unfortunate as having occurred after the cataract extraction with which it has no aetiological connection, though I am thankful to the mishap as it brought back the patient with this rare disorder.

Diagnosis.-The question of Hodgkin's disease can easily be ruled out as it is a disease of young adult males: No lymphatic glands are enlarged; spleen is normal; no anaemia-except for the recent slight occasional pyrexia, the so-called Pel-Ebstein's fever did not occur at the onset. On the whole there is no appearance of malignancy or impending fatality to suggest the similar reticulo-endothelial disorder. Though radiologically positive, I consider the chest lesions are healed sarcoidosis of the lung.

The only other disease simulating sarcoid is uveo-parotid fever. I have not so far seen a case though a lot of literature has been published. In fact sarcoidosis includes very often in its symptomatology Heerfordt's syndrome. The more common generalised glandular involvement, facial paralysis and the initial high fever being absent in my case leaves uveo-parotid fever out of consideration.

Though the slight pyrexia, the roentgenological adenopathy, absence of caseation and the weak or negative Mantoux, common characteristics of sarcoid and uveo-parotid were present in my case, the added subconjunctival tumour, the dermopathy along with the uveitis clinches the diagnosis of sarcoid.

\section{ANNOTATION}

\section{Cacoethes Scribendi}

It was announced not long ago in the papers that the Minister of Supply wishes to reduce the number of forms which have to be filled in by those firms engaged in war production. Many will hear this news with relief, for form filling is rather a nightmare to most people; and if this concession could be applied to all government forms, including our income-tax returns, it would be welcome. But we must say that will not be an easy matter to manage.

We understand that it is impossible to order a pair of spectacles for a soldier without entering details in quadruplicate. We suppose 